\title{
Uma reflexão sobre resolução de problemas na formação de professores que ensinam Matemática
}

\author{
Flávia Sueli Fabiani Marcatto
}

\begin{abstract}
Resumo: Este artigo tem como objetivo a construção de uma perspectiva diferenciada sobre o ensino de Matemática por meio da resolução de problemas para professores e futuros professores. 0 estudo segue uma metodologia de investigação de natureza qualitativa e interpretativa. No desenvolvimento das ações, foram incentivados registros escritos em portfólios com ênfase no processo de resolução de problemas. Dois problemas foram selecionados para intervenções em turmas da Educação Básica. O processo estimulou-os a questionar suas próprias respostas, explorar ideias matemáticas, questionar o problema e seus modos de encontrar a solução, fazer generalizações e transformar um dado problema em novas situações-problema, adaptando-as para suas aulas. Isto evidencia uma concepção de ensino-aprendizagem obtida por via de ação reflexiva e compartilhada que constrói conhecimentos, aprimorando a formação inicial e continuada de professores de Matemática.
\end{abstract}

Palavras-chave: Ensino-Aprendizagem-Avaliação por meio da Resolução de Problemas. Práticas de Discussão. Ações de professores de Matemática.

\section{A reflection on problem solving in teacher education teaching Mathematics}

\begin{abstract}
This article aims to build a differentiated perspective on mathematics teaching by solving problems for teachers and future teachers. The study follows an investigation methodology of qualitative and interpretative nature. In the development of the actions, written records were encouraged in portfolios with an emphasis on the problem-solving process. Two problems were selected for interventions in basic education classes. The process stimulated them to question their own answers, explore mathematical ideas, question the problem and their ways of finding the solution, make generalizations, and transform a given problem into new problem situations, by adapting them to their classrooms. This shows a concept of

teaching and learning obtained through reflexive and shared action that builds knowledge, improving the initial and continued formation of mathematics teachers.
\end{abstract}

Flávia Sueli Fabiani Marcatto

Doutora em Educação Matemática

pela Universidade Estadual Paulista

(UNESP). Professora do Programa de

Pós-Graduação em Ensino de

Ciências da Universidade Federal de

Itajubá (UNIFEI). Minas Gerais, Brasil.

$\checkmark$ flaviafmarcatto@gmail.com

Recebido em 24/04/2019

Aceito em 30/05/2019

Publicado em 01/09/2019

Keywords: Teaching-Learning-Assessment through Problem Solving. Discussion Practices. Actions of Mathematics teachers.

\section{Una reflexión sobre la resolución de problemas en la formación de profesores que enseñan Matemáticas}

Resumen: Este artículo tiene como objetivo la construcción de una perspectiva diferenciada obre enseñanza de Matemáticas por medio de la resolución de problemas para profesores y futuros profesores. El estudio sigue una metodología de investigación de naturaleza cualitativa e interpretativa. En el desarrollo de las acciones se incentivaron registros escritos en portafolios con énfasis en el proceso de resolución de problemas. Dos problemas fueron seleccionados, para intervenciones en grupos de Educación Básica. El proceso estimuló a cuestionar sus propias respuestas, explorar ideas matemáticas, cuestionar el problema y sus maneras de encontrar la solución, hacer generalizaciones y transformar un determinado problema en nuevas situaciones-problema, adaptándolas a sus clases. Esto evidencia una concepción de enseñanzaaprendizaje obtenida por vía de acción reflexiva y compartida que construye conocimientos, perfeccionando la formación inicial y continuada de profesores de Matemáticas.

Palabras clave: Enseñanza-Aprendizaje-Evaluación a través de la resolución de problemas. Prácticas de Discusión. Acciones de profesores de Matemáticas. 


\section{Introdução}

Este artigo tem como objetivo principal apresentar uma perspectiva de trabalho em sala de aula do Ensino Superior amparado pela metodologia de resolução de problemas. As ações aqui descritas foram desenvolvidas no âmbito da disciplina 0 Ensino de Matemática através da Resolução de Problemas, para estudantes do curso Licenciatura em Matemática e do Mestrado Profissional em Ensino de Ciências da Universidade Federal de Itajubá (UNIFEI), no ano de 2016. Participaram deste estudo 11 alunos, sendo seis graduandos e cinco pós-graduandos; destes, nove atuavam como professores em turmas da Educação Básica, em escolas públicas e privadas. Foi acordado com os alunos que as atividades propostas fossem, na medida do possível, aplicadas em suas respectivas turmas de Educação Básica. Nesta disciplina adotamos a definição de problema como "tudo aquilo que não se sabe fazer, mas que se está interessado" (ONUCHIC e ALLEVATO, 2011, p. 81) de alguma forma em resolver.

Assumiu-se a Metodologia de Ensino-Aprendizagem-Avaliação por meio da Resolução de Problemas, tomando como referência aos estudos de Onuchic (1999), Onuchic e Allevato (2004, 2011). Para encaminhar o trabalho, selecionamos os problemas identificados por O Problema dos Sanduíches e O Problema dos Copos.

No desenvolvimento das ações, os estudantes foram orientados a registrá-las e organizálas em portfólio. Esta forma de registro dos trabalhos foi proposta com o objetivo de orientar e facilitar o planejamento de ações futuras, a todos que pretendam utilizar esta metodologia para 0 processo ensino-aprendizagem-avaliação da Matemática por meio da Resolução de Problemas. Os problemas foram selecionados pelo grupo, partindo de critérios de interesse, para intervenções em sala de aula em turmas da Educação Básica, bem como atendendo às necessidades e/ou dificuldades dos estudantes da disciplina em questão.

A seleção e aplicação dos problemas foi realizada após estudos sobre a metodologia proposta pelo Grupo de Trabalho e Estudos em Resolução de Problemas (GTERP), da Universidade Estadual Paulista (UNESP), campus de Rio Claro (SP), onde a Resolução de Problemas é compreendida não só como uma alternativa ao ensino tradicional, mas como uma prática pedagógica educacional, desencadeando discussões sobre como abordá-las em sala de aula. Também considerou-se para qual turma ou etapa da Educação Básica seria mais adequada sua aplicação, levando em conta os conceitos e conteúdos matemáticos envolvidos na resolução; como ampliar estes problemas para contemplar outros alunos de etapas mais avançadas da Educação Básica; e quais estratégias devem ser consideradas para a resolução do problema e para garantir a aprendizagem dos alunos. 
As propostas, ações e reflexões presentes nestes portfólios não são definitivas, nem tão pouco pretende-se abordar de uma única maneira o ensino de Matemática a partir da resolução de problemas. As situações-problema apresentadas neste artigo são uma contribuição dos estudos sobre esta temática, bem como uma opção pedagógico-metodológica para estudantes de licenciatura e professores de Matemática.

\section{0 percurso metodológico}

Tendo como objetivo a construção de uma teorização local sobre o ensino de Matemática por meio da resolução de problemas, para professores e futuros professores, este estudo segue uma metodologia de investigação de natureza qualitativa e interpretativa. Para Kilpatrick (2017), uma proposta de resolução de problemas em Matemática envolve sujeitos resolvendo problemas matemáticos, em uma determinada condição. Os problemas propostos permitiram explorações, investigações, interpretações e formulação de novas questões para resolver com significado.

Foi solicitado aos estudantes da disciplina Metodologia de Resolução de Problemas a aplicação dos problemas discutidos, em suas respectivas turmas dos ensinos Fundamental e Médio. Nove dos estudantes da disciplina possuíam turmas em escolas públicas e privadas de Educação Básica, o que permitiu ao grupo realizar as intervenções. Esses estudantes foram orientados a realizar registros escritos, nos portfólios, de todos as etapas.

Para a elaboração de portfólios, foi solicitado aos alunos da disciplina de Resolução de Problemas, o registro de todas as atividades, permitindo refletir sobre 0 trabalho realizado, revisando processos e decisões e estratégias, articulando ideias. Para Silva e Sá-Chaves (2008), o portfólio tem sido utilizado em várias áreas de formação profissional, cumprindo um papel importante em diferentes contextos educativos. É uma estratégia que potencializa a construção do conhecimento de forma reflexiva, com vistas à uma progressiva emancipação dos sujeitos em formação. Representa a criação de uma cultura de registro e documentação, que favorece os processos do ensino e de aprendizagem, em especial ao permitir construir um registro dos seus métodos de resolver as situações-problema.

\section{Aspectos fundamentais da metodologia de sala de aula}

Optando pela concepção de problema proposta por Onuchic e Allevato (2011), para quem se trata de uma situação desconhecida que mobiliza conhecimentos para a sua solução, o grupo de estudantes da disciplina O Ensino da Matemática através da Resolução de Problemas produziu reflexões e encaminhamentos nos portfólios que podem ser úteis para os professores que 
pretendem utilizar esta metodologia. Os problemas aqui expostos foram selecionados pelo grupo, partindo de critérios de interesse para aplicação em turmas de alunos da Educação Básica.

Considerando o que se pretende com os problemas discutidos, o planejamento das aulas considerou momentos de introdução e compreensão dos problemas, de trabalho autônomo, acompanhado pela professora, de discussão e reflexão e momentos de síntese e reelaboração.

Atendendo à perspectiva destacada, definiu-se fundamentos para o trabalho com os problemas: a) seleção de problemas geradores, visando à construção de um novo conceito ou procedimento; b) compreensão dos problemas, buscando identificar aqueles correlatos e processos de resolução; e c) apresentação das soluções, discutindo e analisando estratégias de resolução.

Quanto ao trabalho do professor no sentido de oportunizar a discussão reflexiva dos estudantes, considerou-se os seguintes fundamentos: i) observar, estimular e acompanhar a resolução dos problemas por eles; ii) incentivar a mobilização de conhecimentos prévios; iii) discutir e analisar soluções certas, erradas ou feitas por diferentes processos; iv) guiar e mediar as discussões coletivas; e v) desafiar os estudantes a ir além do problema, formulando novas questões ou novos problemas.

Dessa forma, propõe-se que o trabalho, em sala de aula, baseado nos fundamentos descritos acima possa promover reflexões sobre a metodologia de resolução de problemas na formação inicial e continuada de professores que ensinam Matemática.

Este artigo apresenta momentos de discussão, sobre os processos de resolução, de dois problemas geradores, realizados na disciplina e posteriormente em turmas da Educação Básica. Eles foram selecionados por serem ilustrativos, tanto pelos problemas propostos, quanto pelas estratégias de resolução dos professores e alunos.

A análise desses momentos é parte das reflexões dos portfólios produzidos na disciplina, a partir dos problemas: o Problema dos Sanduíches e o Problema dos Copos.

\section{Um pouco de história}

Historicamente, o ensino de Matemática pode ser organizado em seis fases, conforme apresentam Lambdin e Walcott (2007) ${ }^{1}$ apud Onuchic e Allevato (2011). Essas fases influenciaram

\footnotetext{
${ }^{1}$ LAMBDIN, Diana V.; WALCOTT, Crystal. Changes through the years: connections between psychological learning theories and the school Mathematics curriculum. In: MARTIN, W. Gary; STRUTCHENS, Marilyn E.; ELLIOT, Portia C. (Ed.). The Learning of Mathematics. Reston: NCTM, 2007, p. 3-25.
} 
o contexto da época, considerando as correntes filosóficas e psicológicas que mais influenciavam a educação. No Brasil também pode-se perceber estas influências, porém talvez tardiamente.

\begin{abstract}
Tais fases merecem atenção porque cada uma delas corresponde a um período em que a educação, em geral, estava caminhando através de mudanças radicais e fundamentais e cada uma introduzia práticas novas e inovadoras para a Educação Matemática. A essas razões, acrescenta-se o fato de que algumas das fases apontadas também foram vivenciadas em outros lugares do mundo, e exerceram forte influência nos rumos que o trabalho com a matemática escolar tomou a partir de então. (ONUCHIC e ALLEVATO, 2011, p. 77)
\end{abstract}

A primeira fase aconteceu por volta das décadas de 1920 e 1930, nas quais o ensino da Matemática centrava-se em facilitar o cálculo por meio do exercício e da prática, o que era conseguido com a memorização de fatos e algoritmos e uma rotina de exercícios em séries, com passos definidos. A partir de 1930 até os anos de 1950, a teoria da Gestalt influenciou a educação e o ensino da Matemática passou a ter como foco a compreensão das ideias e habilidades aritméticas.

Nas décadas de 1960 e 1970, com a influência das teorias socioculturais e da psicologia do desenvolvimento, surge a preocupação com a compreensão da estrutura das disciplinas, com a sistematização dos conteúdos de Matemática. Difunde-se, então, a Matemática Moderna que pretendia à uma organização curricular; há um retorno à aprendizagem mecânica de fatos e algoritmos para o desenvolvimento de habilidades de cálculo.

A partir dos anos 1980, a tendência é a metodologia de resolução de problemas e os processos de pensamento na Matemática. Volta-se à ideia da aprendizagem por descoberta e ainda se propõem a aprendizagem da Matemática a partir da resolução de problemas. Nos anos 1990 surge a preocupação com a alfabetização matemática e o desenvolvimento de currículos baseados em padrões, orientados ao aluno, mas também o foco na preparação para os testes de proficiência. A resolução de problemas continua como proposta para o ensino da Matemática.

A sistematização da resolução de problemas como metodologia no ensino dessa disciplina tem início em 1945, com a publicação do livro How to solve it de George Polya, considerado o precursor da resolução de problemas, e fortalecimento com a publicação dos Principles and Standards for School Mathematics (NCTM, 2000).

O problema é olhado como um elemento que pode disparar um processo de construção de conhecimento. Sob esse enfoque, problemas são propostos ou formulados de modo a contribuir para a formação dos conceitos antes mesmo de sua apresentação em linguagem formal. $\mathrm{O}$ foco está na ação por parte do aluno. A resolução de problemas como uma metodologia de ensino passa a ser o lema das pesquisas e estudos de Resolução de Problemas para os anos de 1990. (ONUCHIC, 1999, p. 207) 
Desde a antiguidade, egípcios, chineses e gregos ocupavam-se com a resolução de problemas matemáticos para compreender questões do dia a dia. O ser humano, ao deparar-se com o mundo e tentar entendê-lo, adaptá-lo e adaptar-se a ele, procura soluções para os problemas que surgem, e muitas vezes, estas soluções envolvem os conhecimentos matemáticos que foram desenvolvendo ao longo de sua existência. Seu raciocínio lógico-matemático garante, em diversas situações-problema, o entendimento e a compreensão do mundo que o cerca e a resolução de problemas que se impõem nas tarefas diárias.

A Educação Matemática apropriou-se da metodologia de resolução de problemas, porém existem concepções diferentes sobre como abordá-la. Uma delas é a abordagem de ensino sobre a resolução de problemas, na qual ensina-se sobre estratégias para resolver problemas. Outra abordagem, ensinar matemática para resolver problemas, coloca o foco no ensino dos conceitos matemáticos com vista a resolver problemas. Já a abordagem do ensino da Matemática por meio da resolução de problemas, muda o foco trazendo a metodologia de resolução de problemas para a centralidade do ensino da Matemática. Assim,

implementar a Metodologia de Ensino-Aprendizagem-Avaliação de Matemática através da Resolução de Problemas, exige do professor e dos alunos novas posturas e atitudes com relação ao trabalho em sala de aula. O professor precisa preparar, ou escolher, problemas apropriados ao conteúdo ou ao conceito que pretende construir. Precisa deixar de ser 0 centro das atividades, passando para os alunos a maior responsabilidade pela aprendizagem que pretendem atingir. Os alunos, por sua vez, devem entender e assumir essa responsabilidade. Esse ato exige de ambos, portanto, mudanças de atitude e postura, o que, nem sempre, é fácil conseguir. (ONUCHIC e ALLEVATO, 2011, p. 82)

Ao ensinar Matemática a partir da resolução de problemas, o problema é colocado como o ponto de partida para a construção dos conhecimentos matemáticos. Novos conteúdos, conceitos e estratégias são construídos a partir do problema proposto, com a participação ativa dos alunos e orientação do professor. 0 processo ensino-aprendizagem-avaliação nesta abordagem requer do aluno uma postura colaborativa como construtor do seu próprio conhecimento e do professor, uma postura de condutor do processo, planejando, instigando e orientando o processo de construção dos alunos.

\section{Problemas geradores}

\subsection{0 problema dos Sanduíches}

A primeira situação-problema selecionada é intitulada O Problema dos Sanduíches, que foi considerada pelos estudantes como proposta interessante para a abordagem de assuntos referentes à justiça na divisão de recursos. 
Quadro 1: 0 problema dos sanduíches ${ }^{2}$

Lara, Isa e Cris foram a um piquenique. Lara levou dois sanduíches, Isa três, mas Cris esqueceu-se de levar comida. Se as três repartirem o alimento igualmente e Cris pagar a Lara e a Isa um total de R $\$ 5,00$ pelos sanduíches repartidos, quanto cada uma delas (Lara e Isa) deverá receber em dinheiro?

Fonte: Acervo da Pesquisa

Esse problema foi selecionado, discutido e analisado considerando os fundamentos elencados para o trabalho com os problemas e para o trabalho do professor. Posteriormente, foi aplicado em três turmas: um grupo de alunos do $7^{\circ}, 8^{\circ}$ e $9^{\circ}$ anos do Ensino Fundamental, em uma escola de Educação Básica, de tempo integral; uma turma em preparação para a Olimpíada Brasileira de Matemática das Escolas Públicas (OBMEP); e uma turma da Educação de Jovens e Adultos (EJA). Aqui descreveremos a intervenção realizada com uma turma da EJA.

As soluções foram discutidas com os estudantes na disciplina de Resolução de Problemas. $\mathrm{O}$ objetivo foi fazê-los vivenciar a resolução de problemas como uma metodologia de ensino e, a partir dessa experiência, se colocar no papel de aluno resolvedor. A seguir, algumas resoluções discutidas entre os estudantes e a professora responsável pela disciplina.

A primeira solução discutida foi baseada em desenhos, os quais representam a quantidade de sanduíches que Lara e Isa possuíam e a divisão desses entre as três meninas, como se pode observar no Quadro 2.

Quadro 2: Divisão dos sanduíches entre Isa, Lara e Cris

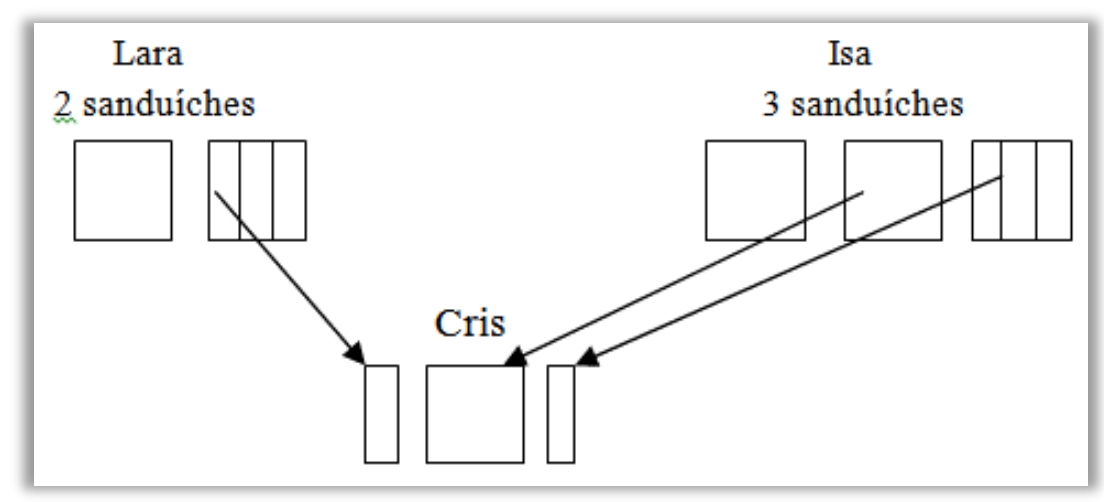

Fonte: Acervo da Pesquisa

A divisão ilustrativa dos sanduíches iniciou com um sanduíche inteiro para cada menina. Assim, Isa dá um sanduíche para Cris, visto que ela levou a maior quantidade e, com essa ação, fica com a mesma quantidade de sanduíches que Lara. Desse modo, nova divisão foi realizada,

20 problema foi traduzido e adaptado de um material impresso obtido em um curso de formação, no ano de 1996, pela autora. 
agora com os sanduíches extras de Lara e Isa, entre as três meninas. Dividiu-se cada sanduíche extra, em três partes iguais, obtendo seis partes ao todo. Essas foram distribuídas entre as três meninas, ou seja, cada uma ficou com duas partes de sanduíches. Logo, ao final da divisão, cada menina ficou com um sanduíche inteiro mais duas partes do sanduíche que fora dividido em três.

Concluída a partilha dos sanduíches, chegou o momento de Cris pagar a quantia que havia levado, $R \$ 5,00$, às demais meninas. Como pode ser visto no Quadro 2, Lara deu um terço de um sanduíche para Cris, enquanto Isa deu um sanduíche inteiro mais um terço de sanduíche. A divisão foi realizada considerando que um sanduíche inteiro poderia ser dividido em três partes iguais. Portanto, Cris recebeu cinco partes iguais de sanduíches, sendo que uma parte foi dada por Lara e quatro por Isa. Cada parte de sanduíche equivale a $R \$ 1,00$, o que significa que Lara recebeu $R \$ 1,00$ e Isa, $R \$ 4,00$.

Outra resolução, discutida coletivamente, dividiu-se em três partes todos os cinco sanduíches. Assim, Lara teria seis partes e Isa nove partes, já que tinham dois e três sanduíches respectivamente. Com essa divisão, haveria 15 pedaços iguais de sanduíches, sendo que cada menina ficaria com cinco pedaços, como podemos ver no Quadro 3.

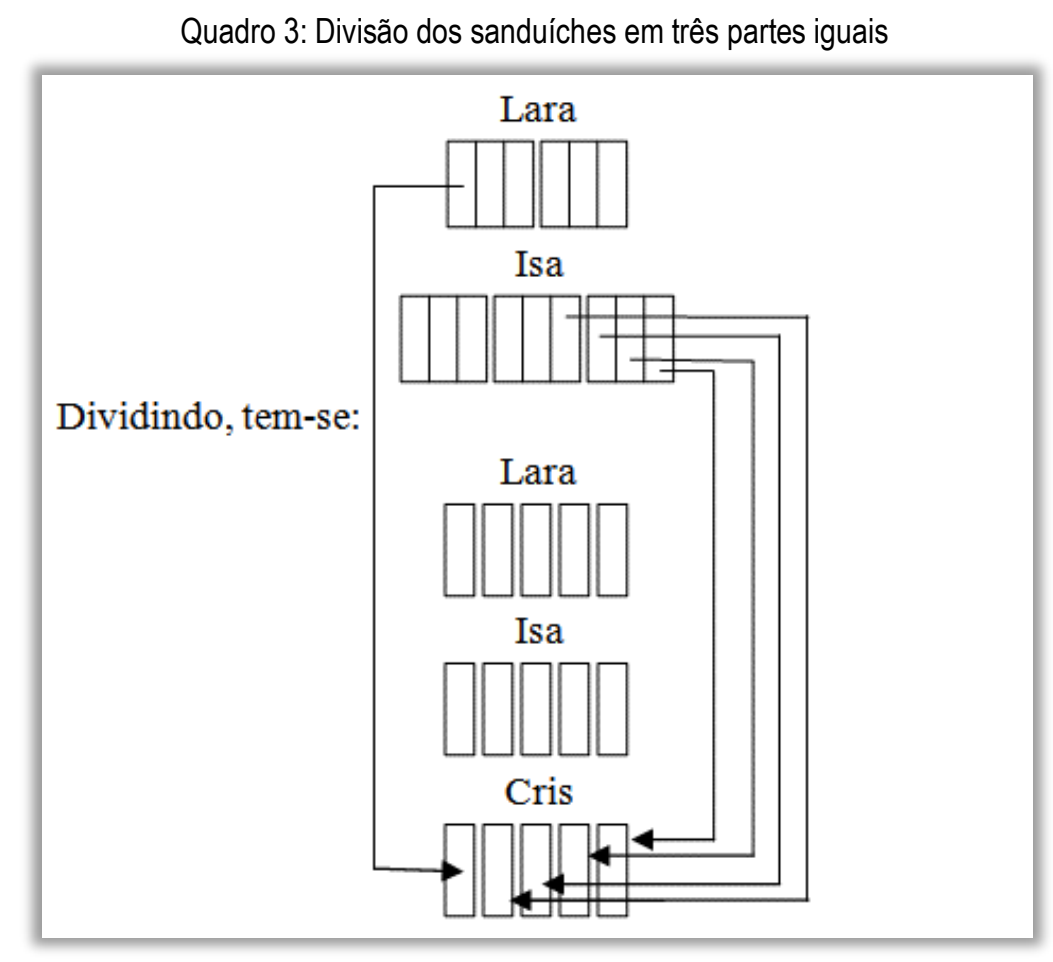

Fonte: Acervo da Pesquisa

Dessa forma, Lara que tinha seis pedaços, deu um pedaço para Cris e ficou com cinco, enquanto Isa que tinha nove pedaços, deu quatro pedaços à Cris. Assim, se considerarmos cada pedaço equivalente a $R \$ 1,00$, Isa receberia $R \$ 4,00$ e Lara ficaria com $R \$ 1,00$. 
Além das resoluções apoiadas por desenhos, foram discutidas duas soluções realizadas aritmeticamente, as quais serão detalhadas a seguir e se assemelham, uma vez que recorrem à divisão numérica entre a quantidade total de sanduíches (cinco), pelo total de meninas no piquenique (três), resultando em uma dízima periódica $(1,66666 \ldots)$.

A primeira solução utilizou o valor aproximado 1,6. Em seguida, 1,6 do total de sanduíches que cada menina levou para saber quanto cada uma deu a Cris. Lara levou dois sanduíches e comeu 1,6 sanduíches, portanto contribuiu com 0,4 sanduíches para Cris. Isa levou três sanduíches e, também, comeu 1,6 sanduíches, portanto contribuiu com 1,4 sanduíches para Cris. Considerando os valores obtidos, 1,6 representa a quantidade de sanduíches que cada menina tinha direito de comer. Assim, Isa deu 1,4 sanduíches à Cris e Lara, deu 0,4 sanduíche, totalizando 1,8 sanduíches para Cris. Essa solução apresenta uma inconsistência com a situação-problema apresentada, pois não respeitou a condição de divisão em partes iguais, dos sanduíches, entre as três meninas.

Esse resultado diferente do encontrado com a utilização de representação gráfica, feita anteriormente, suscitou uma discussão reflexiva entre os estudantes da disciplina. 0 fato de termos realizado um truncamento no resultado da divisão $(5 \div 3)$, para a dízima periódica 1,66666... ficando 1,6, utilizou-se de uma aproximação incorreta que causou uma diferença nos valores finais dos sanduíches repartidos.

Por fim, a última resolução discutida tem o raciocínio semelhante ao anterior, porém considerou $1,6666 \ldots$ como resultado da divisão entre a quantidade total de sanduíches e a quantidade de meninas. Logo, como Lara tinha dois sanduíches, ela deu para Cris 0,3333... sanduíche, enquanto Isa contribuiu com 1,3333... sanduíches, uma vez que ela tinha três sanduíches. Com isso, se Cris pagar um total de $\mathrm{R} \$ 5,00$ pelos sanduíches consumidos, pode-se constatar que o valor que Isa receberá de Cris é de $R \$ 4,00$ e Lara receberá $R \$ 1,00$. Essa resolução apresenta contas com números decimais, nesse caso dízimas periódicas, o que poderia oportunizar a introdução desse assunto para alunos dos anos finais do Ensino Fundamental.

Nas discussões coletivas, alguns estudantes defenderam que essa resolução era mais complexa e que teriam dificuldade em chegar nesse resultado com seus alunos. Diante dessa questão, uma estudante da disciplina se propôs a trabalhar esse problema, de forma lúdica, com a sua turma de EJA, com o intuito de desenvolver maior interação da situação-problema com a realidade dos alunos, auxiliando na construção de representações e significados, contribuindo para a compreensão e enriquecimento da realidade de vida dos alunos jovens e adultos. 
Para isso, a intervenção foi constituída por alguns momentos que antecederam a situaçãoproblema, os quais buscou-se introduzir alguns aspectos que auxiliassem os alunos na interpretação, análise e utilização de mecanismos para chegar à solução. A turma da EJA era constituída por 12 alunos, com idades entre 20 e 65 anos.

Em um primeiro momento, a professora responsável pela turma da EJA organizou atividades preliminares, usando moedas e cédulas confeccionadas pelos alunos, com o objetivo de simular situações do dia a dia desses jovens e adultos, pagando e recebendo troco.

No segundo momento, vivenciaram situações que os levaram a manipular e visualizar a representação numérica em fração (relação parte-todo). Em seguida, a situação-problema foi lida e interpretada pelos alunos, indagando e proporcionando a turma uma dinâmica oral sobre a situação e a solução para o problema.

Dando sequência, no quarto momento a professora mediou o trabalho, disponibilizando aos alunos o material, constituído de pão de forma, presunto e queijo, para confeccionarem sanduíches, de modo individual. Assim, com os sanduíches prontos, os alunos foram distribuídos em trios para que pudessem solucionar a situação proposta pelo professor, fazendo uso do material concreto construído até então: sanduíches, moedas e cédulas confeccionadas.

Por fim, se deu a socialização das soluções do problema, sendo que um trio foi selecionado para apresentar a sua resolução para a turma, em forma de teatro, na qual os alunos foram caracterizados e tinham crachás de identificação conforme o nome das personagens, assim como utilizaram os materiais construídos durante a intervenção.

Acerca do trabalho supracitado, pode-se afirmar que as resoluções apresentadas não são as únicas possíveis para esse problema, assim como podem ser encontrados soluções incorretas e que vale a pena discuti-las. Além disso, pode-se partir desse problema para criar outro, ampliando-o e modificando-o de modo a suprir as necessidades dos alunos, assim como pode ser proposto, aos alunos, uma pesquisa de preços dos ingredientes que compõem os sanduíches, objetivando a dar origem a novas situações-problema.

Nessa perspectiva, ao efetuarem as contas, envolvendo alguns preços, podem resultar em dízimas periódicas ou não periódicas. O aluno, ao entrar em contato com estas quantidades, pode imaginar que o resultado de seus cálculos esteja errado, já que até então, parece inconcebível pensar que a razão entre dois números inteiros positivos resulte em um número com infinitas casas decimais, de forma periódica, motivando o trabalho com novos conceitos e com novas abordagens de ensino. 
As estratégias de resolução do problema desde as mais simples, envolvendo desenhos e materiais concretos, são importantes para a introdução de conceitos matemáticos básicos, para alunos dos anos iniciais do Ensino Fundamental (turmas regulares) e do Ensino Fundamental da EJA. Este problema pode ser utilizado também para abordar questões culturais e de justiça, assim como pode ser ampliado, gerando novas situações-problema. Em relação a isso, foi realizada uma ampliação do problema, a qual propõe a introdução de outros conceitos matemáticos que podem ser abordados numa segunda fase da aplicação do problema ou em anos subsequentes, Ensino Médio por exemplo, como se pode observar no Quadro 4.

Quadro 4: Ampliação do Problema dos Sanduíches

Lara, Isa e Cris foram a um piquenique. Lara levou dois sanduíches de mortadela. Isa levou três de presunto e queijo. No entanto, Cris não conseguiu preparar os sanduíches a tempo para levar e optou por levar o dinheiro para pagar o que consumiu. Sabendo que:

As três amigas dividiram os sanduíches igualmente, inclusive as porções de sabor;

Os pães dos sanduíches não se diferenciavam, sendo todos pães franceses;

Todos os pães pesavam, em média, 50 gramas;

O preço de 100 gramas de pão francês é de $R \$ 0,90$;

Em cada lanche de mortadela havia duas fatias, enquanto nos demais lanches havia uma fatia de cada item;

Cada fatia de mortadela, presunto e queijo pesava aproximadamente 30 gramas;

$O$ preço de 100 gramas de mortadela é $R \$ 1,80$;

$O$ preço de 100 gramas de presunto é $R \$ 2,20$;

O preço de 100 gramas de queijo é $R \$ 2,60$;

Qual será o preço que Cris deverá pagar a Lara e a Isa, respectivamente, considerando o preço de todos os itens presente nos sanduíches consumidos por ela? Qual o valor total que Cris terá gasto para participar do piquenique?

Fonte: Acervo da Pesquisa

\subsection{0 problema dos copos}

O segundo problema escolhido foi o Problema dos Copos $^{3}$, no qual trabalhou-se com várias formas de resolução, em turmas do Ensino Fundamental. $O$ interessante da aplicação deste problema foi a dificuldade encontrada pelos alunos em chegar ao resultado.

\footnotetext{
${ }^{3}$ O problema foi traduzido e adaptado de um material impresso obtido em um curso de formação, no ano de 1996,
} pela autora. 
Quadro 5: Problema dos Copos

Um copo cheio de água pesa $275 \mathrm{~g}$, este mesmo copo, quando cheio de óleo pesa $225 \mathrm{~g}$. Dois copos idênticos aos anteriores, um com a metade de água e o outro com a metade de óleo pesam juntos $375 \mathrm{~g}$. Quanto pesa, em gramas, o copo vazio?

\section{Fonte: Acervo da Pesquisa}

Da mesma forma que ocorreu com o primeiro problema, 0 problema dos copos foi aplicado em turmas do $7^{\circ}, 8^{\circ}$ e $9^{\circ}$ anos, em preparação para a OBMEP, todas do Ensino Fundamental. As várias possibilidades de resolução do problema, desde as mais simples envolvendo desenhos $\mathrm{e}$ materiais concretos, foram incentivadas e discutidas durante as aulas da disciplina, na universidade, bem como com os alunos da Educação Básica. As resoluções feitas pelos alunos dessas turmas e pelos estudantes da disciplina serão apresentadas a seguir. A primeira resolução foi realizada por meio da escrita, a qual podemos observar no Quadro 6.

Quadro 6: Resolução escrita do Problema dos Copos

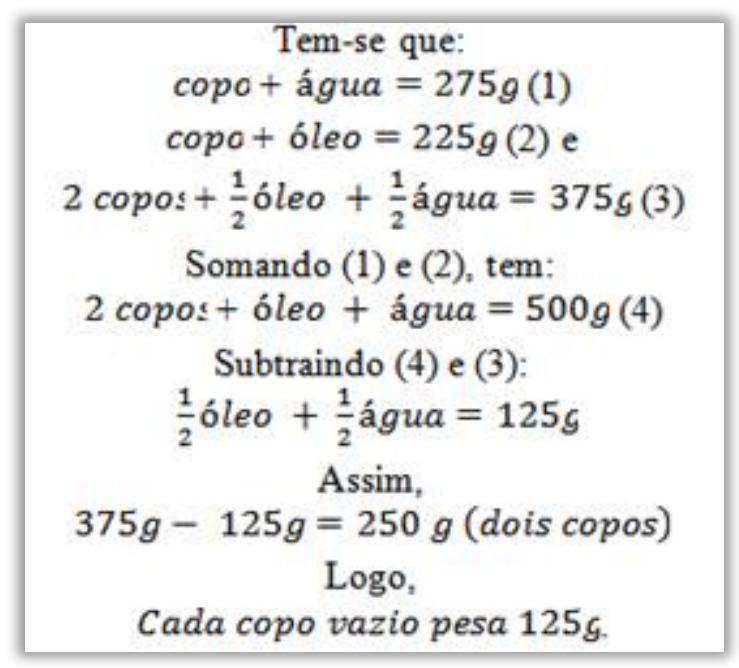

Fonte: Acervo da Pesquisa

A segunda resolução se trata de um pensamento puramente algébrico, na qual a incógnita $x$ representa a massa do copo vazio. Logo, para encontrar esse valor, formulou-se a equação que representa a soma da massa de dois copos vazios, meio de água e meio de óleo, sendo que a água e o óleo foram representados por $275 g-x$ e $225 g-x$, respectivamente, como podemos observar na equação seguinte.

$$
\frac{1}{2}(275 g-x)+\frac{1}{2}(225 g-x)+2 x=375 g
$$

A partir disso, para encontrar o peso do copo vazio, basta resolver a equação. Esse desenvolvimento da equação se encontra no Quadro 7. 
Quadro 7: Resolução da equação do quadro 7

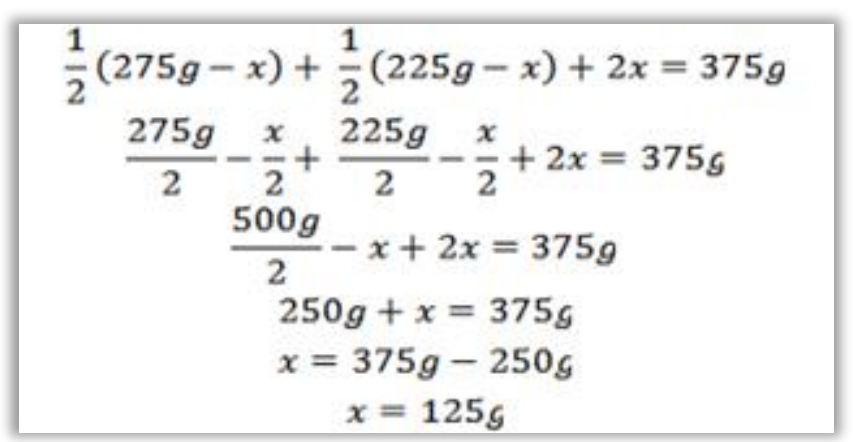

Fonte: Acervo da Pesquisa

A terceira solução se apoiou em um raciocínio algébrico, usando o processo de resolução de equações baseado no princípio de adição de igualdades, com o auxílio da noção de equilíbrio, por meio do modelo de uma balança. Inicialmente, converteu-se todos os dados do problema em linguagem simbólica, simulando uma representação de equilíbrio dos pratos de uma balança, como mostra o Quadro 8.

Quadro 8: Resolução do problema dos Copos

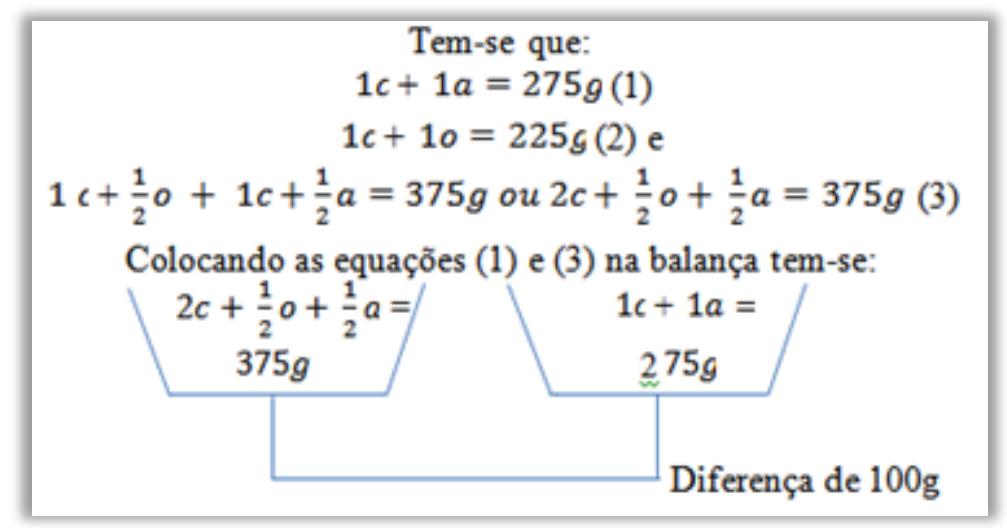

Legenda: a -água; c - copo vazio; o - óleo

Fonte: Acervo da Pesquisa

É possível observar que o lado esquerdo possui $100 \mathrm{~g}$ a mais que a quantidade que está no prato da direita, no modelo da balança. Para manter o equilíbrio acrescentou-se $100 \mathrm{~g}$ ao lado direito, como ilustrado no Quadro 9.

Quadro 9: Acréscimo de $100 \mathrm{~g}$ para equilibrar a balança

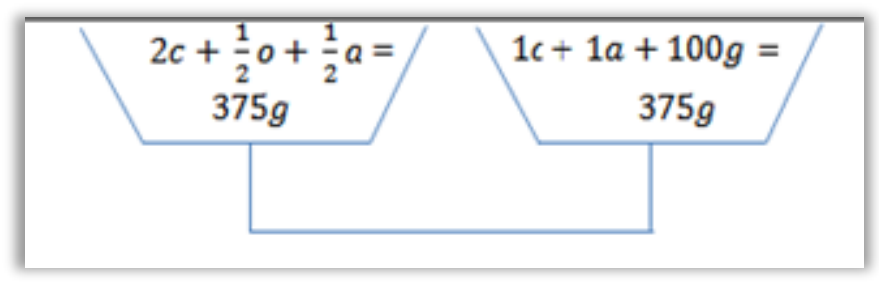

Legenda: a -água; c - copo vazio; o - óleo

Fonte: Acervo da Pesquisa 
Após esse acréscimo, pode-se perceber que, em ambos os lados da balança, tem-se um copo vazio. Logo, podemos retirá-lo dos dois lados, mantendo assim o equilíbrio. Após essa retirada, multiplicou-se ambos os lados por dois, evitando operar com números fracionários. Essas ações podem ser visualizadas no Quadro 10.

Quadro 10: Retirada dos copos e ajustes nas operações aritméticas

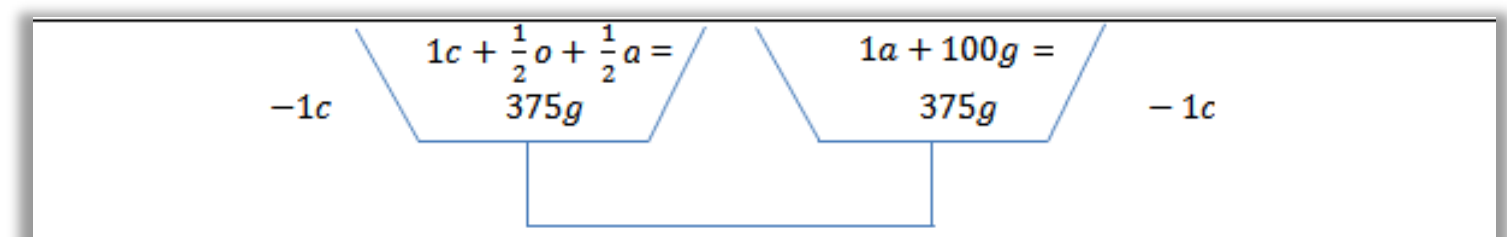

Logo, temos que $1 c+\frac{1}{2} o+\frac{1}{2} a=1 a+100 \mathrm{~g}$. Multiplicando por dois, em ambos os lados, tem-se que:

$$
2 c+1 o+1 a=2 a+200 g
$$

Legenda: a - água; c - copo vazio; 0 - óleo

Fonte: Acervo da Pesquisa

Assim, desenvolve-se essa equação, subtraindo $1 a$ de ambos os lados e, em seguida, substitui-se $1 c+1 o$ por $225 g$ no lado esquerdo, isso pode ser feito, pois representa a igualdade (2), descrita no Quadro 8. Com isso, obtém-se o resultado descrito no Quadro 11.

Legenda: a - água; c - copo vazio; o - óleo

Fonte: Acervo da Pesquisa

Por fim, substituindo a igualdade $1 a=1 c+25 g$ na expressão (1), descrita no Quadro 8, o desenvolvimento da igualdade encontrada pode ser visto no Quadro 12.

Quadro 12: Resolução final

$$
\begin{aligned}
& \text { Substituindona igualdade (1), } 1 c+1 a=275 g, \text { tem-se: } \\
& \qquad \begin{array}{c}
1 c+1 c+25 g=275 g \\
2 c+25 g=275 g \\
2 c=275 g-25 g \\
2 c=250 g \\
c=125 g
\end{array}
\end{aligned}
$$

Legenda: a - água; c - copo vazio

Fonte: Acervo da Pesquisa 
Uma quarta solução foi proposta, usando operações aritméticas. Iniciou-se com a divisão da massa copo cheio de água por dois: $275 \mathrm{~g} \div 2=137,5 \mathrm{~g}$. Em seguida, fez-se a mesma operação com a massa do copo cheio de óleo, chegando ao valor de 112,5 g. Então, adicionou-se os valores encontrados, obtendo $250 \mathrm{~g}$. Após essa operação, realizou-se a diferença entre $375 \mathrm{~g}$ e $250 \mathrm{~g}$, resultando $125 \mathrm{~g}$. Assim, concluiu-se que o copo vazio tinha $125 \mathrm{~g}$ de massa, como ilustrado no Quadro 13. Ao lado direito do quadro estão as operações aritméticas substituídas pela notação simbólica.

Quadro 13: Explicação da resolução aritmética

\begin{tabular}{c|c}
$275+2=137,5$ & $(1 c+1 a)+2=\left(\frac{1}{2} c+\frac{1}{2} a\right)$ \\
$225 \div 2=112,5$ & $(1 c+1 c) \div 2=\left(\frac{1}{2} c+\frac{1}{2} o\right)$ \\
$137,5+112,5=250$ & $\left(\frac{1}{2} c+\frac{1}{2} a\right)+\left(\frac{1}{2} c+\frac{1}{2} o\right)=\left(1 c+\frac{1}{2} a+\frac{1}{2} c\right)$ \\
$375-250=125$ & $\left(2 c+\frac{1}{2} a+\frac{1}{2} o\right)-\left(1 c+\frac{1}{2} a+\frac{1}{2} c\right)=(1 c)$
\end{tabular}

Legenda: a -água; c - copo vazio; o - óleo Fonte: Acervo da Pesquisa

Outra solução para esse problema, semelhante ao raciocínio feito na quarta solução, foi realizada a partir da diferença entre o valor da massa de dois copos, um com meia quantidade de óleo e o outro com meia quantidade de água, e o valor da massa de um copo cheio de água, obtendo o valor de $100 \mathrm{~g}$. Em seguida, fez-se a mesma operação, retirando um copo cheio de óleo, resultando em $150 \mathrm{~g}$. Após essas operações, adicionou-se os resultados, $100 \mathrm{~g} \mathrm{e} 150 \mathrm{~g} \mathrm{e}$, em seguida, dividiu-se o resultado por dois, obtendo $125 \mathrm{~g}$ correspondente à massa de um copo vazio. Podemos ver esse raciocínio também na forma algébrica no Quadro 14.

Quadro 14: Representação algébrica da resolução

\begin{tabular}{|c|c|}
\hline $375-275=100$ & $\left(2 c+\frac{1}{2} a+\frac{1}{2} o\right)-(1 c+1 a)=\left(1 c-\frac{1}{2} a+\frac{1}{2} o\right)$ \\
$375-225=150$ & $\left(2 c+\frac{1}{2} a+\frac{1}{2} o\right)-(1 c+1 c)=\left(1 c+\frac{1}{2} a-\frac{1}{2} o\right)$ \\
$100+150=250$ & $\left(1 c-\frac{1}{2} a+\frac{1}{2} o\right)+\left(1 c+\frac{1}{2} a-\frac{1}{2} o\right)=(2 c)$ \\
$250 \div 2=125 \mathrm{~g}$ & $(2 c)+2=(1 c)$
\end{tabular}

Legenda: a - água; c - copo vazio; o - óleo

Fonte: Acervo da Pesquisa

A última solução apresentada, e discutida com os estudantes, se trata de um raciocínio desenvolvido apenas com os copos cheios de água e de óleo. Primeiro, adiciona-se os valores de massa do copo cheio de água com o copo cheio de óleo, obtendo $500 \mathrm{~g}$. Em seguida, multiplicouse $375 \mathrm{~g}$ por dois, chegando ao valor de $750 \mathrm{~g}$, representando quatro copos: um com água, um 
com óleo e os demais vazios. Subtraiu-se os valores encontrados, $750 \mathrm{~g}$ e $500 \mathrm{~g}$, e dividiu-se por dois, obtendo $125 \mathrm{~g}$, ou seja, a massa do copo vazio. A solução algébrica está no Quadro 15.

Quadro 15: Explicação algébrica para a resolução

\begin{tabular}{|c|c|}
\hline $275+225=500$ & $(1 c+1 a)+(1 c+1 c)=(2 c+1 a+1 c)$ \\
$375 \times 2=750$ & $\left(2 c+\frac{1}{2} a+\frac{1}{2} c\right) \times 2=(4 c+1 a+1 c)$ \\
$750-500=250$ & $(4 c+1 a+1 c)-(2 c+1 a+1 c)=(2 c)$ \\
$250 \div 2=125 \mathrm{~g}$ & $(2 c) \div 2=(1 c)$
\end{tabular}

Legenda: a - água; c - copo vazio; 0 - óleo

Fonte: Acervo da Pesquisa

Além dessas soluções, foi discutida em sala uma solução inválida, uma vez que fora encontrado o resultado de $125 \mathrm{~g}$, mas o valor apesar de ser a resposta do problema, não representava a massa do copo vazio. Essa iniciou-se com a adição da massa de um copo cheio de água e um copo cheio de óleo, resultando $500 \mathrm{~g}$. Desse valor, subtraiu-se o valor da massa de dois copos, um com metade de água e o outro com a metade de óleo, resultando no valor que acreditava-se ser a massa do copo vazio, $125 \mathrm{~g}$. Mas esse valor representava a massa de meia quantidade de água e meia quantidade de óleo, ou seja, apenas a massa dos líquidos, como pode ser visto no Quadro 16, a qual apresenta também a solução algébrica.

Quadro 16 - Representação algébrica da solução inválida

\begin{tabular}{|c|c|}
\hline $275+225=500$ & $(1 c+1 a)+(1 c+1 c)=(2 c+1 a+1 c)$ \\
$500-375=125$ & $(2 c+1 a+1 c)-\left(2 c+\frac{1}{2} a+\frac{1}{2} c\right)=\left(\frac{1}{2} a+\frac{1}{2} c\right)$
\end{tabular} \mid $\begin{gathered}\text { Legenda: a - água; } c-\text { copo vazio; } 0 \text { - óleo } \\
\text { Fonte: Acervo da Pesquisa }\end{gathered}$

Diante das soluções apresentadas, pode-se considerar que esse problema possui diversas formas de resolver, utilizando de raciocínios aritmético e algébrico e ainda de representações gráficas. Sabemos ainda que essas não são as únicas maneiras de encontrar a resposta correta. 0 interessante desse problema para a disciplina foi a rica discussão realizada em cada resolução, uma vez que buscava-se compreender o raciocínio utilizado para que identificássemos o que esse representava. Foram discutidas e analisadas nas discussões coletivas 15 soluções diferentes, apresentadas pelos estudantes participantes da disciplina. Dentre elas, algumas incorretas que foram fundamentais para a reflexão dos professores e futuros professores, buscando a compreensão de seus próprios erros e de seus alunos. 


\section{Considerações}

No decorrer da disciplina O Ensino de Matemática através da Resolução de Problemas, a partir dos problemas geradores O Problema dos Sanduíches e O Problema dos Copos, mediados pela metodologia de ensino-aprendizagem-avaliação de Matemática por meio de Resolução de Problemas, ofereceu-se oportunidades aos estudantes para resolver problemas de Matemática utilizando estratégias de resolução diversificadas. Os momentos de discussões coletivas foram essenciais para que os processos de raciocínio pudessem emergir na sala de aula.

Para D'Ambrósio (2017), o professor construtivista promove a reflexão do sujeito a partir de provocações do meio e interações com outros. Ainda segundo a mesma autora, 0 conhecimento se estabelece para o sujeito como saber quando a solução do problema encontrado é válida ou não. Quando o sujeito não encontra meios de solucionar a situação-problema ele procura novos meios, explorações, caminhos e interpretações. Desse modo, o papel do professor é selecionar problemas que tenham o potencial de desequilibrar os saberes e adicionar novas perspectivas ao conhecimento do aluno.

Nesse trabalho, conceitos e conteúdos dos ensinos Fundamental e Médio foram (re)construídos e (re)significados pelos professores e futuros professores, não mais de uma forma tradicional, como já tinham vivenciado e não compreendido, mas com a participação ativa, com compreensão e significado.

Existe uma tradição matemática escolar que envolve a exposição de um tópico específico pelo professor, que posteriormente define as tarefas para os alunos. As tarefas possuem características particulares: toda a informação dada é exata, e não necessita de maior exploração, ou seja, toda a informação dada é necessária e suficiente para resolver os exercícios. Um destaque desse trabalho foi observar uma nova postura diante de atividades matemáticas ampliando a exploração como a leitura de enunciados e sua interpretação, elaboração de estratégias e utilizando-as, realizando verificações e testando a razoabilidade das soluções, além de fazer relação de conceitos matemáticos e elaborar conexões entre eles.

A proposta da disciplina não foi a de ensinar a resolver problemas e sim a de usar problemas para ensinar Matemática e promover uma atitude positiva em relação à resolução de problemas. As questões que devemos fazer ao escolher um problema são: Quais conceitos e procedimentos matemáticos são possíveis de ensinar por meio deste problema? Para quais anos da Educação Básica poderia ser trabalhado? É possível gerar outros problemas a partir de um problema inicial? Assim, a Matemática quando explorada desta maneira, ganha significado. 
O envolvimento dos estudantes, professores e futuros professores, no processo estimulou-os a questionar suas próprias respostas, a explorar ideias matemáticas, a questionar 0 problema e seus modos de encontrar a solução, a fazer generalizações e a transformar um problema em novas situações-problema, adaptando-as para suas aulas na Educação Básica. Isto evidencia uma concepção de ensino e de aprendizagem obtida por via de ação reflexiva e compartilhada que constrói conhecimentos, aprimorando a formação inicial e continuada de professores de matemática.

\section{Referências}

D'AMBRÓSIO, Beatriz Silva. O professor-pesquisador diante da produção escrita dos alunos. In ONUCHIC, Lourdes de la Rosa; LEAL JUNIOR, Luiz Carlos; PIRONEL, Márcio. Perspectivas para a resolução de problemas. São Paulo: Editora Livraria da Física, 2017, p. 109-129.

KILPATRICK, Jeremy. Reformulando: abordando a resolução de problemas matemáticos como investigação. In ONUCHIC, Lourdes de la Rosa; LEAL JUNIOR, Luiz Carlos; PIRONEL, Márcio. Perspectivas para a resolução de problemas. São Paulo: Editora Livraria da Física, 2017, p. 85107.

ONUCHIC, Lourdes de la Rosa, ALLEVATO, Norma Suely Gomes. Novas reflexões sobre o ensino-aprendizagem de Matemática através da resolução de problemas. In: BICUDO, Maria Aparecida Viggiani; BORBA, Marcelo de Carvalho. (Org.). Educação Matemática: pesquisa em movimento. São Paulo: Cortez, 2004. p. 213-231.

ONUCHIC, Lourdes de la Rosa, ALLEVATO, Norma Suely Gomes. Pesquisa em Resolução de Problemas: caminhos, avanços e novas perspectivas. Bolema, Rio Claro, v. 25, n. 41, p. 73-98, dez. 2011.

ONUCHIC, Lourdes de la Rosa. Ensino-aprendizagem de Matemática através da Resolução de Problemas. In: BICUDO, Maria Aparecida Viggiani. (Org.). Pesquisa em Educação Matemática. São Paulo: EdUNESP, 1999, p.199-218.

SILVA, Roseli Ferreira da, SÁ-CHAVES, Idália. Formação reflexiva: representações dos professores acerca do uso de portfólio reflexivo na formação de médicos e enfermeiros. Interface - Comunicação, Saúde, Educação, Botucatu, v. 12, n .27, p. 721-734, out./dez. 2008. 